\title{
Interleukin 6 regulates psoriasiform inflammation-associated thrombosis
}

\author{
Yunmei Wang, ${ }^{1}$ Jackelyn B. Golden, ${ }^{2}$ Yi Fritz, ${ }^{2}$ Xiufen Zhang, ${ }^{2}$ Doina Diaconu, ${ }^{2}$ Maya I. Camhi, ${ }^{2}$ \\ Huiyun Gao, ${ }^{1}$ Sean M. Dawes, ${ }^{2}$ Xianying Xing, ${ }^{3}$ Santhi K. Ganesh, ${ }^{4}$ Johann E. Gudjonsson, ${ }^{3}$ \\ Daniel I. Simon, ${ }^{1}$ Thomas S. McCormick, ${ }^{2}$ and Nicole L. Ward ${ }^{2}$ \\ 'Division of Cardiovascular Medicine, University Hospitals Cleveland Medical Center and Case Western Reserve University, \\ Cleveland, Ohio, USA, ${ }^{2}$ Department of Dermatology, Case Western Reserve University, Cleveland, Ohio, USA. ${ }^{3}$ Department \\ of Dermatology, ${ }^{4}$ Department of Internal Medicine, Division of Cardiovascular Medicine, and Department of Human \\ Genetics, University of Michigan, Ann Arbor, Michigan, USA.
}

Psoriasis patients are at increased risk of heart attack and stroke and have elevated MRP8/14 levels that predict heart attack. The KC-Tie2 psoriasiform mouse model exhibits elevated MRP8/14 and is prothrombotic. Mrp14-/- mice, in contrast, are protected from thrombosis, but, surprisingly, $\mathrm{KC}-\mathrm{Tie} 2 \times \mathrm{Mrp}^{14^{-/-}}$mice remain prothrombotic. Treating KC-Tie2xMrp14-/- mice with anti-IL23 19 antibodies reversed the skin inflammation, improved thrombosis, and decreased IL-6. In comparison, IL- 6 deletion from KC-Tie2 animals improved thrombosis despite sustained skin inflammation, suggesting that thrombosis improvements following IL-23 inhibition occur secondary to IL- 6 decreases. Psoriasis patient skin has elevated IL- 6 and IL-6 receptor is present in human coronary atheroma, supporting a link between skin and distant vessel disease in patient tissue. Together, these results identify a critical role for skin-derived IL-6 linking skin inflammation with thrombosis, and shows that in the absence of IL- 6 the connection between skin inflammation and thrombosis comorbidities is severed.

Authorship note: Y. Wang, J.B. Golden, and $Y$. Fritz contributed equally to this work.

Conflict of interest: The authors declare that no conflict of interest exists.

Submitted: July 5, 2016

Accepted: October 28, 2016

Published: December 8, 2016

Reference information:

JCl Insight. 2016;1(20):e89384

doi:10.1172/jici.nsight.89384.

\section{Introduction}

Myeloid-related protein 14 (MRP14) is a member of the S100 calcium-modulated protein family and is involved in autoimmunity, chronic inflammation, and cancer $(1,2)$. The biological functions of MRP14 include regulating vascular inflammation and the promotion of leukocyte recruitment to sites of vascular injury (3). MRP14 forms a heterodimer with MRP8, and plasma levels of MRP8/14 predict first and recurrent heart attacks (3-5). Moreover, transcriptional profiling of platelets from patients with acute coronary syndromes identified MRP14 as an acute myocardial infarction gene. Mice engineered to lack MRP14 (Mrp14 $\left.{ }^{\prime-}\right)$ develop less vasculitis, restenosis, and atherosclerosis (3), and have prolonged thrombosis occlusion times (6).

Psoriasis is a chronic, inflammatory skin disease that affects $\sim 2 \%$ of the general population. Psoriasis patients are at an increased risk of developing and dying of a cardiovascular event (7-11). A potential pathogenic role for MRP8/14 in psoriasis is supported by the finding that MRP8/14 genes are located within the psoriasis PSORS4 susceptibility region (12), and that serum and skin MRP8/14 levels are increased in psoriasis and psoriatic arthritis patients $(13,14)$ and in psoriasiform mouse models $(15-17)$. However the significance of MRP8/14 in psoriasis pathogenesis, including its contribution to increased cardiovascular risk, remains unclear.

The KC-Tie2 mouse is a well-accepted murine model of psoriasis, in which the angiopoietin receptor Tie2 is ectopically expressed in keratinocytes resulting in a skin phenotype that phenocopies human psoriasis at the histological, cellular, and molecular levels and that improves following treatment with clinically efficacious drugs and fails to improve in response to drugs not useful in patients (18-22). KC-Tie2 mice develop a chronic and spontaneous psoriasis-like skin phenotype with keratinocyte proliferation and differentiation, increased angiogenesis and inflammatory cell infiltration of $\mathrm{T}$ cells, dendritic cells, and macrophages and elevated IL-23/IL-17A signaling. Importantly, KC-Tie2 mice have elevated skin and serum levels of MRP14 and are prothrombotic (17).

Given that MRP14-deficient mice have prolonged thrombus occlusion times (6), and KC-Tie2 mice demonstrate shortened times to thrombotic occlusion concomitant with increased skin and circulating 
A

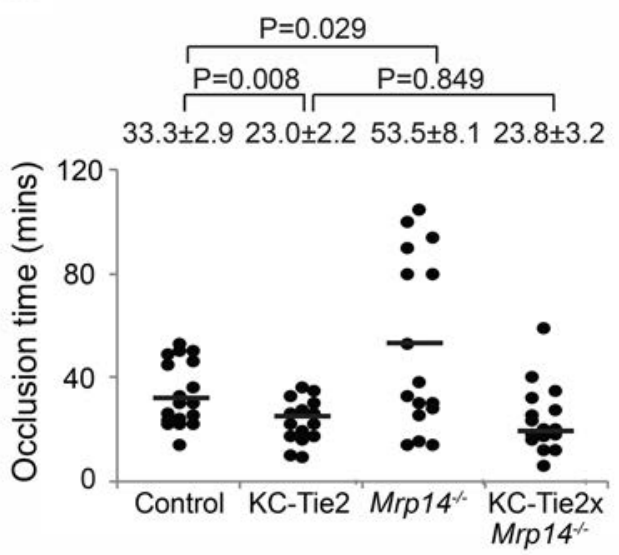

C
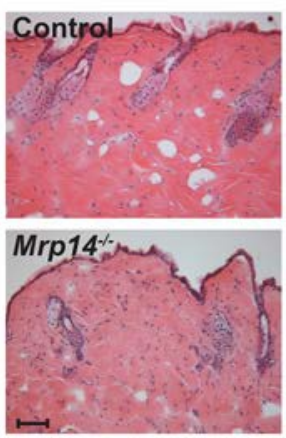

B

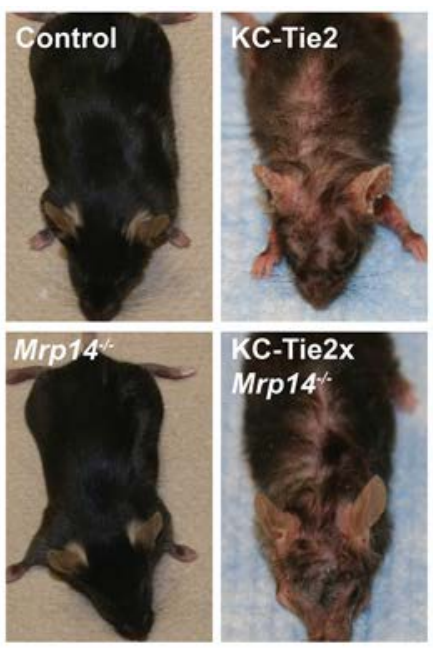

D

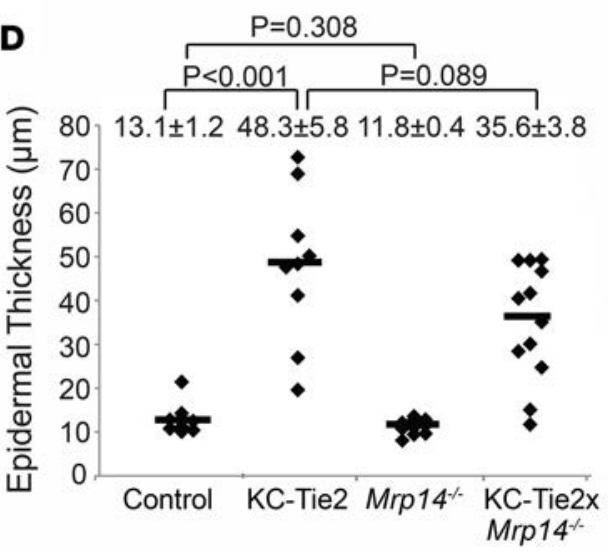

Figure 1. MRP14 deficiency in KC-Tie2 mice fails to resolve the prothrombotic phenotype or improve skin inflammation. (A) Occlusion times (minutes) following rose bengal-induced photochemical injury of the carotid artery in control $(n=18)$, KC-Tie2 ( $n=15), M_{r p 14^{-/-}}$ ( $n=17)$, and KC-Tie2xMrp14 ${ }^{-/-}(n=16)$ mice. (B) Gross phenotype of KCTie2xMrp14/- mice in comparison with control, KC-Tie2, and Mrp14-/- mice. (C) Representative images of $\mathrm{H} \& \mathrm{E}$-stained dorsal skin sections of control, KC-Tie2, Mrp14/-, and KC-Tie2xMrp14 ${ }^{-/-}$mice. Scale bar: $25 \mu \mathrm{m}$. (D) Quantification of epidermal thickness ( $\mu \mathrm{m})$ of H\&Estained dorsal skin sections of control $(n=9)$, KC-Tie2 $(n=9), M_{14}{ }^{--}(n=13)$, and KC-Tie2xMrp14 ${ }^{-/-}(n=12)$ mice. Values shown represent the mean \pm SEM. Each dot represents 1 individual mouse. Data were analyzed using a Student's $t$ test. $P$ values are as indicated.

MRP14 levels (17), we hypothesized that a deficiency of MRP14 in $\mathrm{KC}$-Tie2 mice would resolve the skin inflammation and lengthen the time to thrombus formation. However, we determined that deletion of MRP14 from KC-Tie2 mice (KCTie2xMrp $14^{--}$) failed to improve thrombosis and skin inflammation, perhaps as a result of sustained

increased levels of IL-23 and IL-6. Anti-IL-23p19 treatment of KC-Tie2xMrp14-1 mice reversed the skin inflammation, lengthened time to arterial thrombotic occlusion, decreased IL- 6 , and led to modest reductions in circulating monocytes. Genetic deletion of IL-6 in KC-Tie2 animals (KC-Tie2xIL-6 ${ }^{-/}$) failed to improve skin inflammation but did improve thrombosis that corresponded with decreases in circulating monocytes, neutrophils, and platelets. We identify a critical role for elevated skin IL-6 as a regulator of psoriasis-related thrombosis, independent of skin inflammation and demonstrate that improvement in thrombosis corresponds best with decreases in circulating neutrophils and platelets.

\section{Results}

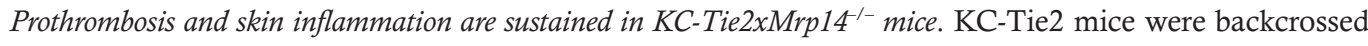
with $M r p 14^{--}$mice and increases in cutaneous Tie2 protein and deficiency in MRP14 protein confirmed in KC-Tie2xMrp14 ${ }^{--}$mice (Supplemental Figure 1, A and B; supplemental material available online with this article; doi:10.1172/jci.insight.89384DS1). To determine whether the absence of MRP14 in KC-Tie2 mice corrects the shortened thrombus formation time, we measured the time to occlusive thrombus formation in KC-Tie2xMrp $14^{-1-}$ mice using the rose bengal carotid artery thrombosis injury model. Consistent with prior observations $(6,17), \mathrm{KC}$-Tie 2 mice form an occlusive thrombus more quickly (prothrombotic) compared with control C57BL/ 6 mice $(23.0 \pm 2.2$ vs. $33.3 \pm 2.9$ minutes, $P=0.008)$ and $M r p 14^{-1-}$ mice take significantly longer $(53.5 \pm 8.1$ vs. $33.3 \pm 2.9$ minutes, $P=0.029)$. The occlusion time for $\mathrm{KC}-\mathrm{Tie} 2 \mathrm{xMrp} 14^{-/-}$mice was not lengthened and was comparable to KC-Tie2 animals ( $23.8 \pm 3.2$ vs. $23.0 \pm 2.2$ minutes, respectively, $P=0.849$, Figure 1A), suggesting that the deficiency of MRP14 in KC-Tie2 mice does not improve the prothrombotic phenotype.

MRP14 deficiency did not improve the skin inflammation in KC-Tie2 mice (Figure 1, B-D), and KCTie2 and KC-Tie2xMrp14 $14^{-1}$ mice appeared similar in terms of gross appearance (Figure 1B). H\&E stain-

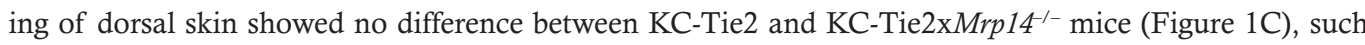


Table 1. Transcript changes in mouse skin and statistical results on the strain comparisons

\begin{tabular}{|c|c|c|c|c|c|c|c|c|c|}
\hline \multicolumn{5}{|c|}{ Average \pm SEM } & \multicolumn{5}{|c|}{ Mann-Whitney $U$ test } \\
\hline & Control & KC-Tie2 & Mrp14 ${ }^{-/-}$ & KC-Tie2XMrp14\%-/- & $\begin{array}{l}\text { WT vs. } \\
\text { KC-Tie2 }\end{array}$ & $\begin{array}{l}\text { WT vs. } \\
\text { Mrp14-/- }\end{array}$ & $\begin{array}{c}\text { WT vs. } \\
\text { KC-Tie2xMrp14-/- }\end{array}$ & $\begin{array}{c}\text { KC-Tie2 vs. } \\
\text { KC-Tie2xMrp14+/- }\end{array}$ & $\begin{array}{c}\text { Mrp14 }{ }^{-/-} \text {vs. } \\
\text { KC-Tie2xMrp14/- }\end{array}$ \\
\hline LI37 & $0.00045 \pm 0.00016$ & $0.00324 \pm 0.00123$ & $0.00039 \pm 0.00012$ & $0.00208 \pm 0.00052$ & 0.004 & 0.867 & 0.009 & 0.518 & 0.001 \\
\hline Defb3 & $0.08265 \pm 0.02092$ & $0.10170 \pm 0.02486$ & $0.006840 \pm 0.01964$ & $0.04706 \pm 0.01630$ & 0.402 & 0.404 & 0.210 & 0.030 & 0.839 \\
\hline Tnf & $0.00445 \pm 0.00096$ & $0.03090 \pm 0.00669$ & $0.00762 \pm 0.00141$ & $0.00705 \pm 0.00251$ & $<0.001$ & 0.089 & 0.970 & $<0.001$ & 0.284 \\
\hline II12a & $0.00005 \pm 0.00002$ & $0.00040 \pm 0.00024$ & $0.00004 \pm 0.00001$ & $0.00171 \pm 0.00116$ & 0.024 & 0.443 & 0.732 & 0.138 & 0.434 \\
\hline 1123 & $0.00598 \pm 0.00222$ & $0.00308 \pm 0.00094$ & $0.00092 \pm 0.00054$ & $0.01938 \pm 0.01868$ & 0.508 & 0.006 & 0.087 & 0.087 & 0.052 \\
\hline II1a & $0.00290 \pm 0.00034$ & $0.03239 \pm 0.00608$ & $0.00334 \pm 0.00038$ & $0.00726 \pm 0.00158$ & $<0.001$ & 0.526 & 0.017 & $<0.001$ & 0.019 \\
\hline Ifn & $0.00010 \pm 0.00005$ & $0.00027 \pm 0.00006$ & $0.00027 \pm 0.00008$ & $0.00047 \pm 0.00016$ & 0.012 & 0.077 & 0.009 & 0.621 & 0.369 \\
\hline II17f & $0.00003 \pm 0.00001$ & $0.00073 \pm 0.00029$ & $0.00003 \pm 0.00001$ & $0.00166 \pm 0.00043$ & $<0.001$ & 0.92 & $<0.001$ & 0.119 & $<0.001$ \\
\hline 1122 & $0.00003 \pm 0.00001$ & $0.00016 \pm 0.00007$ & $0.00005 \pm 0.00003$ & $0.00020 \pm 0.00007$ & 0.015 & 0.664 & 0.003 & 0.382 & 0.003 \\
\hline$\| 17 c$ & $0.00067 \pm 0.00054$ & $0.01335 \pm 0.00445$ & $0.00011 \pm 0.00003$ & $0.00514 \pm 0.00145$ & $<0.001$ & 0.133 & 0.002 & 0.053 & $<0.001$ \\
\hline Klk6 & $0.00364 \pm 0.00201$ & $0.08415 \pm 0.02299$ & $0.00932 \pm 0.00461$ & $0.06318 \pm 0.01901$ & $<0.001$ & 0.443 & $<0.001$ & 0.305 & $<0.001$ \\
\hline C3 & $0.02043 \pm 0.01035$ & $0.02917 \pm 0.01456$ & $0.01961 \pm 0.00436$ & $0.03959 \pm 0.01240$ & 0.573 & 0.483 & 0.191 & 0.216 & 0.068 \\
\hline$c f b$ & $0.01287 \pm 0.0059$ & $0.01941 \pm 0.00744$ & $0.01910 \pm 0.00443$ & $0.02125 \pm 0.00828$ & 0.355 & 0.128 & 0.160 & 0.821 & 0.885 \\
\hline
\end{tabular}

that acanthosis (epidermal thickness) was increased significantly in KC-Tie2 and KC-Tie2xMrp14 ${ }^{-1}$ mice compared with control and $M r p 14^{-1}$ mice. No improvement (decreased acanthosis) was observed between KC-Tie2 and KC-Tie2xMrp14 ${ }^{-1}$ animals (Figure 1D). The lack of improvement in acanthosis most likely reflects sustained inflammation and cell proliferation, evidenced by the accumulation of cutaneous inflammatory cells in the skin of $\mathrm{KC}-\mathrm{Tie} 2 \mathrm{xMrp} 14^{-1-}$ mice, including $\mathrm{CD} 11 \mathrm{c}^{+}, \mathrm{F} 4 / 80^{+}, \mathrm{CD} 4^{+}$, and $\mathrm{CD} 8^{+}$cells and Ki67 $7^{+}$keratinocytes (Supplemental Figure 1C and Supplemental Table 1).

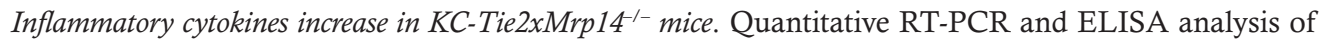
skin from KC-Tie2 and KC-Tie2xMrp14--identified increases in many proinflammatory transcripts compared with control mice including Ll37, Il1a, Il22, Il12a, Il23, Il17c, Il17f, Ifng, and Klk6 (Table 1). We were particularly interested in IL-23, IL-17A, and IL-6, as these cytokines increased in KC-Tie2xMrp $14^{1-}$ mice at the mRNA (Figure 2, A-C) and protein levels (Figure 2, D-F) compared with littermate controls.

KC-Tie2xMrp14 ${ }^{-1}$ mice treated with anti-IL-23p19 antibodies have improved skin inflammation and thrombosis. Elevated levels of IL-23, IL-17A, and IL-6 in KC-Tie2xMrp14/-- mice provided targets for inhibition studies. Antibodies targeting the IL-23/IL17A inflammatory pathways are highly efficacious in psoriasis patients (23), and IL-23 is upstream of IL-17A; therefore, to inhibit both cytokines we treated KC-Tie2xMrp14-1mice with anti-IL-23p19 function-blocking antibodies, and then examined the effects on thrombosis and skin acanthosis. Functional blockade of IL-23 in KC-Tie2xMrp $14^{-1-}$ mice significantly improved the skin inflammation compared with control mouse levels (Figure 3, A-C) and improved (lengthened) the occlusion time compared with IgG-treated animals $(35.0 \pm 5.2$ vs. $13.0 \pm 1.6$ minutes, $P=0.003$, Figure $3 \mathrm{D})$. Inhibition of IL-23p19 in KC-Tie2xMrp14--mice decreased cutaneous IL-6 protein compared with IgG-treated animals (13.5 \pm 1.7 vs. $28.3 \pm 10.0 \mathrm{pg} / \mathrm{ml}, P=0.044$, one-tailed $t$ test, Figure $3 \mathrm{E})$.

IL-6 deficiency improves thrombus occlusion times in KC-Tie2 mice independent of skin inflammation. Elevated IL-6 in KC-Tie2xMrp14--mice (Figure 2, C and F) along with the decreased expression of IL-6 in anti-IL23p19-treated KC-Tie2xMrp14-- mice (Figure 3E) suggest a potential role for IL-6 in the promotion of thrombosis and the psoriasiform skin inflammation. We therefore investigated whether deficiency of IL-6 improves skin inflammation and occlusion time in KC-Tie2 mice. KC-Tie2 mice were backcrossed with $I L-6^{-1-}$ mice and KC-Tie2, KC-Tie2xIL- $6^{-1-}, I L-6^{-/}$, and control mice underwent arterial thrombosis. $I L-6^{-1}$ mice had occlusion times similar to those of control mice $(29.2 \pm 4.9$ vs. $22.1 \pm 2.0$ minutes, $P=0.204)$ and KC-Tie2 mice clotted more quickly than control animals (15.8 \pm 1.7 vs. $29.2 \pm 4.9$ minutes, $P<0.024)$. In the absence of IL-6, KC-Tie2xIL- $6^{-1}$ animals showed a significant lengthening of time to thrombus occlusion compared with KC-Tie2 mice ( $30.0 \pm 3.0$ vs. $15.8 \pm 1.7$ minutes, $P<0.001$, Figure $4 \mathrm{~A})$.

The gross phenotype of $\mathrm{KC}$-Tie $2 \times I L-6^{-1}$ mice appeared similar to KC-Tie2 mice and histological examination of skin from KC-Tie2 and KC-Tie $2 \times I L-6^{-1-}$ mice revealed significant increases in acanthosis in both lines compared with control animals, indicating no effect of IL-6 deficiency $(38.0 \pm 2.2$ to $34.4 \pm 2.6 \mu \mathrm{m}, P=0.312$, Figure 4, B-D). This lack of improvement in skin inflammation is consistent 

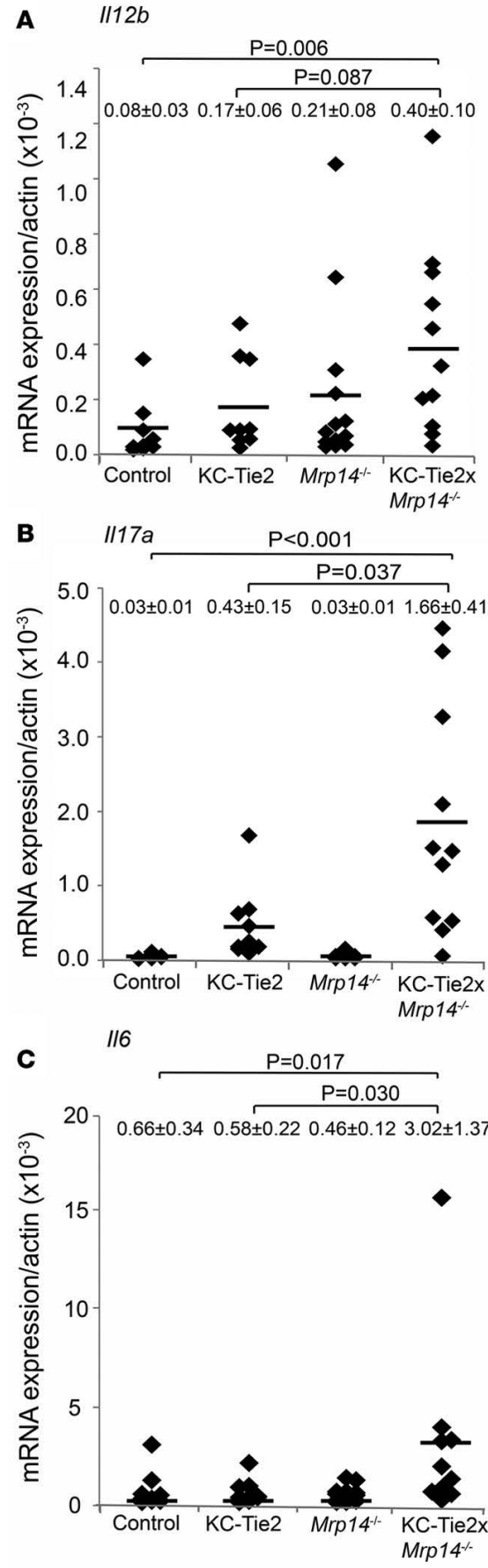

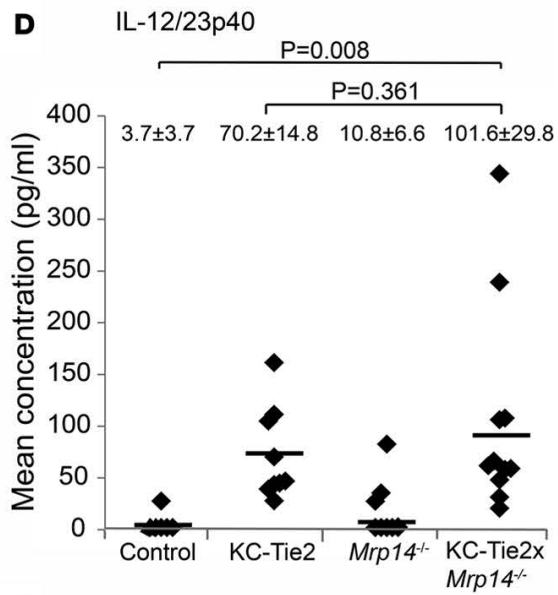

E

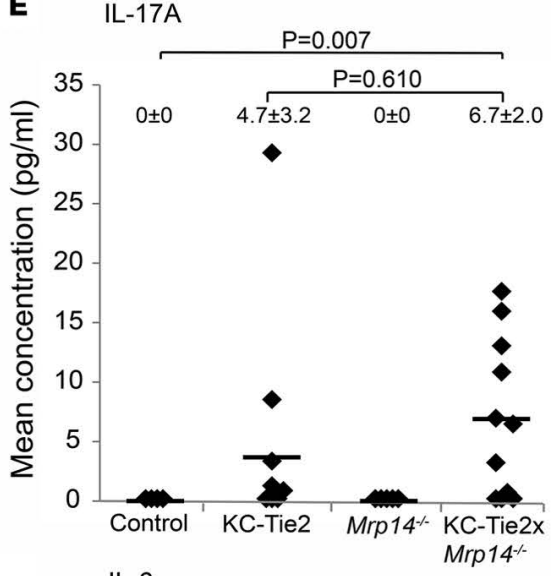

$\mathbf{F}$

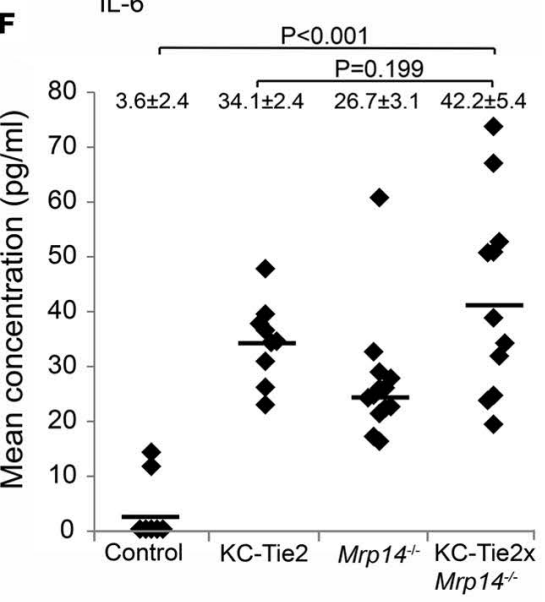

Figure 2. Proinflammatory cytokines increase in KC-Tie2 $\times \mathrm{Mrp14}^{-/-}$mice. Transcript levels of (A) IL-12/23p40, (B) IL-17A, and (C) IL-6 measured using qRT-PCR in control $(n=9)$, KC-Tie2 $(n=9)$, Mrp14 $^{--}(n=13)$, and KC-Tie2xMrp14 ${ }^{-/-}(n=12)$ mice. Protein levels $(\mathrm{pg} / \mathrm{ml})$ measured using ELISA for (D) IL-12/23p40, (E) IL-17A, and (F) IL-6 in skin of control $(n=7)$, KC-Tie2 $(n=9)$, Mrp14 $^{-1-}(n=13)$, and KC-Tie2xMrp14 ${ }^{--}(n=11)$ mice. Values shown represent the mean \pm SEM. Each dot represents 1 individual mouse. qRT-PCR data were analyzed using a nonparametric Mann-Whitney $U$ test. ELISA data were analyzed using a Student's $t$ test. $P$ values are as indicated.

with reports showing a lack of clinical efficacy of IL-6 inhibition in psoriasis patients (24). The sustained acanthosis in KC-Tie $2 \times I L-6^{-1}$ mice likely reflects the ongoing presence and accumulation of $\mathrm{CD}^{+}, \mathrm{CD}^{+}, \mathrm{CD} 11 \mathrm{~b}^{+}$, and $\mathrm{F} 4 / 80^{+}$inflammatory cells in the skin (Figure $4 \mathrm{C}$ and Supplemental Figure 2, A-D). These data suggest that in the absence of IL-6, KC-Tie2 mice are protected from thrombosis despite sustained skin inflammation. Similar findings were observed in the K5-IL17C psoriasis mouse model (25) when backcrossed with $I L-6^{-1-}$ mice $(26.7 \pm 2.2$ versus $9.8 \pm 1.2$ minutes, $P<0.001$, Supplemental Figure 3 ), where we recently determined that the sustained skin inflammation was a result of induction of alternative proinflammatory cytokines (26).

KC-Tie2xIL-6 $6^{-1}$ mice have decreases in circulating platelets, neutrophils, and monocytes. To explore the mechanisms mediating the promotion of carotid arterial thrombosis in KC-Tie2 mice, we examined circulating blood levels of leukocytes, monocytes, platelets, and granulocytes from mice that showed improved occlusion times (KC-Tie2xIL-6 ${ }^{-/}$) and animals that maintained their shortened clotting times (KC-Tie2, KC-Tie2xMrp14--) and compared these with their respective control animals

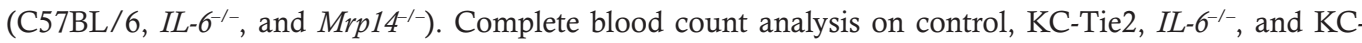
Tie2x $I L-6^{-1-}$ mice identified increases in platelets $(933.3 \pm 42.2$ vs. $635.5 \pm 30.9$ thousand per $\mu 1[\mathrm{k} / \mu 1]$, $P<0.001)$ (Figure 5A), neutrophils $(3.467 \pm 0.422 \mathrm{k} / \mu \mathrm{l}$ vs. $1.232 \pm 0.087, P<0.001)$ (Figure 5B), and monocytes $(0.482 \pm 0.131$ vs. $0.259 \pm 0.025 \mathrm{k} / \mu 1, P=0.124)$ (Figure $5 \mathrm{C}$ ) between KC-Tie2 mice and C57BL/6 mice, although the monocyte $P$ values did not reach significance. In KC-Tie $2 \times M r p 14^{-1}$ mice, which remained prothrombotic (Figure 1A), the increases in these cell populations were maintained, and monocyte numbers further increased compared with KC-Tie2 mice $(0.816 \pm 0.095$ vs. $0.482 \pm 0.131 \mathrm{k} / \mu 1$, $P<0.001$, Figure 5C). In contrast, KC-Tie $2 \times I L-6^{-1}$ mice, which had significantly longer (improved) occlusion times compared with KC-Tie2 animals (Figure 4A), also had significant decreases in circulating platelets $(459.2 \pm 46.0 \mathrm{k} / \mu 1$ vs. $933.3 \pm 42.2, P<0.001)$, neutrophils $(1.26 \pm 0.24$ vs. $3.47 \pm 0.42, P<0.001)$, and monocytes $(0.197 \pm 0.031$ vs. $0.259 \pm 0.025 \mathrm{k} / \mu 1, P=0.057)$, with values dropping to levels comparable to those observed in control animals (Figure 5, A-C). 

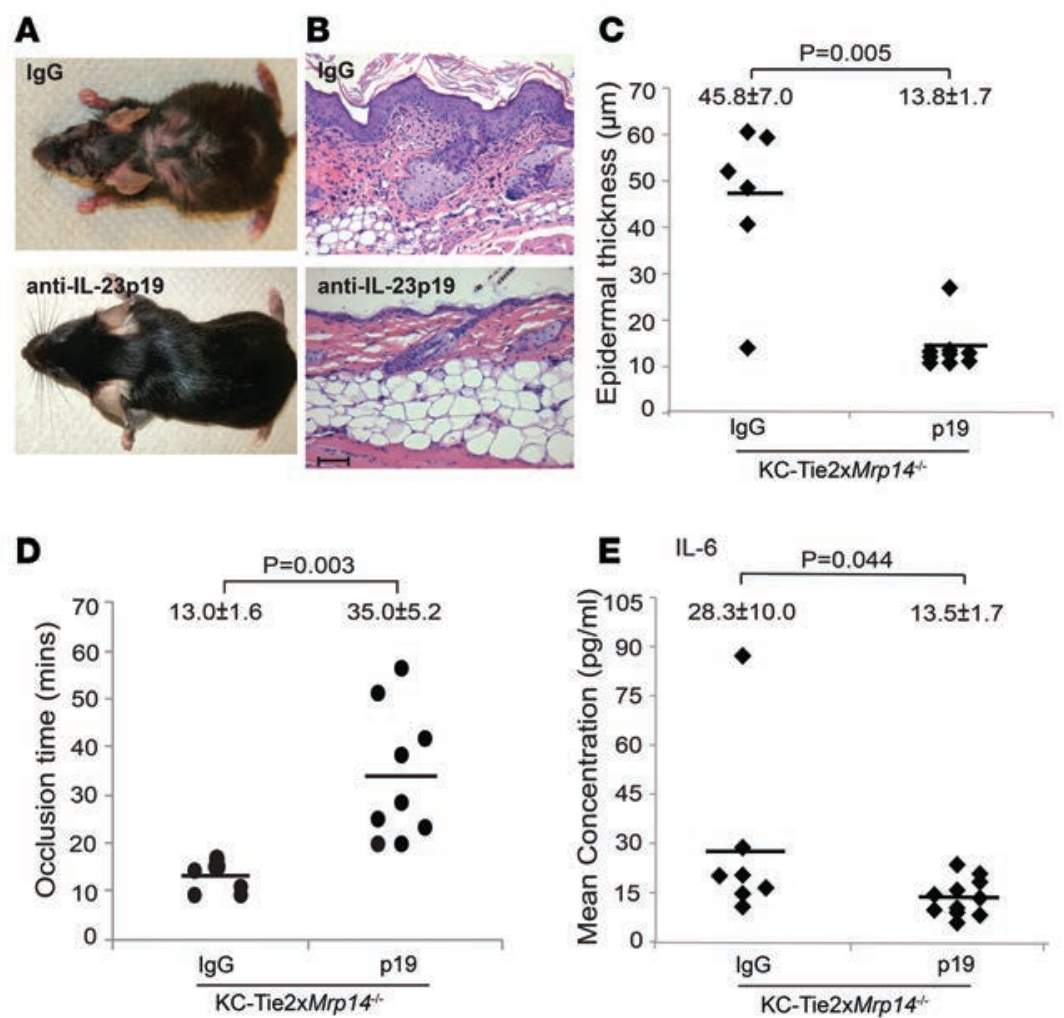

Figure 3. KC-Tie2xMrp14-/- mice treated with functionblocking antibodies targeting IL-23p19 show significant improvement in skin inflammation, prolonged thrombus occlusion time, and decreases in cutaneous IL-6 protein levels. (A) Representative gross phenotype of KC-Tie2 $\mathrm{Mrp}^{-1 /-}$ mice following 6 weeks of treatment with IgG or anti-IL-23p19 antibody. (B) H\&E-stained dorsal skin sections of $\mathrm{KC}-\mathrm{Tie} 2 \mathrm{XMrp14^{-/- }}$ mice treated with IgG or anti-IL-23p19 antibody. Scale bar: $25 \mu \mathrm{m}$. (C) Quantification of epidermal thickness $(\mu \mathrm{m})$ of $\mathrm{H} \& \mathrm{E}$-stained dorsal skin sections of KC-Tie2XMrp14 ${ }^{-/-}$mice treated with IgG ( $n=6)$ or anti-IL-23p19 (p19; $n=9$ ) antibody. (D) Carotid artery occlusion times (minutes) following 6 weeks of treatment with IgG $(n=6)$ or anti-IL-23p19 ( $n=$ 9) antibody. (E) Expression of IL-6 protein (pg/ml), measured using ELISA, in dorsal skin of KC-Tie2xMrp14 ${ }^{-/-}$mice treated with IgG $(n=7)$ or anti-IL-23p19 $(n=11)$ antibodies. Values shown represent the mean $\pm \mathrm{SEM}$. Each dot represents 1 individual mouse. Data were analyzed using a Student's $t$ test. $P$ values are as indicated.

To further explore potential mechanisms mediating the promotion of carotid arterial thrombosis in KC-Tie2 mice, we also examined CD $11 b^{+} L_{6} 6 C^{\text {hi }}$ cells in skin draining lymph nodes using flow cytometry as previously described $(17,27)$. KC-Tie2 mice had significant increases in $\mathrm{CD} 11 \mathrm{~b}^{+} \mathrm{Ly} 6 \mathrm{C}^{\mathrm{hi}}$ cells $(65.1 \% \pm 3.1 \%$, Figure $5 \mathrm{D})$ compared with historical control levels (18.3\%, represented by the dotted line). Mice that had improved occlusion times

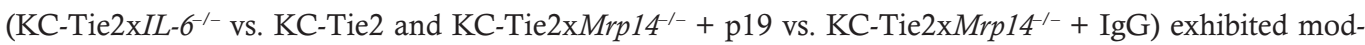
est decreases in $\mathrm{CD}_{11} \mathrm{~b}^{+} \mathrm{Ly} 6 \mathrm{C}^{\mathrm{hi}}$ cells $(55.0 \% \pm 3.2 \%$ vs. $65.1 \% \pm 3.1 \%, P=0.029$ and $50.0 \% \pm 4.8 \%$ vs. $87.3 \% \pm 3.3 \%, P<0.001$, Figure 5D). Animals that maintained shortened (prothrombotic) clotting times

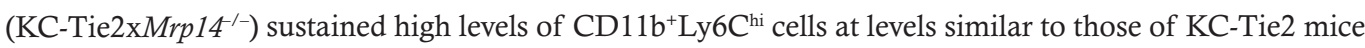
$(58.2 \% \pm 4.2 \%$ vs. $65.1 \% \pm 3.1 \%, P=0.253$, Figure $5 \mathrm{D})$.

Increased IL-6 levels in human psoriasis and atheroma plaques. Our data suggest a critical role for skin inflammation-elicited increases in IL- 6 in the promotion of arterial thrombosis. In psoriasis patients, IL- 6 is increased in lesional skin and sera. IL- 6 is linked with progression of coronary artery inflammation and is known to be proatherogenic $(28,29)$. To further explore the potential link between IL- 6 , inflammation, and atherosclerosis we confirmed increases in IL-6 protein in psoriasis patient lesional skin $(58.4 \pm 33.2 \mathrm{pg} /$ $\mathrm{ml}$ vs. normal healthy control skin $8.8 \pm 4.1 \mathrm{pg} / \mathrm{ml}$, ELISA) and observed increased expression of IL- 6 in lesional psoriatic skin (Figure 6A). We also identified high expression levels of IL-6 and the IL-6 receptor, IL-6R (Figure 6B), in coronary atherosclerotic plaque from cardiac patients. These data provide evidence for a potential role for IL- 6 in the promotion of cardiovascular disease, including increases in skin and serum IL- 6 in psoriasis patients, and the presence of IL- 6 and IL-6R in atherosclerotic plaque of coronary arteries.

\section{Discussion}

Our prior work identified shortened thrombosis times in KC-Tie2 mice (17) accompanied by elevated MRP14 levels in skin and sera. Independent studies completed by our group previously demonstrated

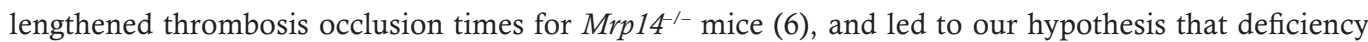
of MRP14 in KC-Tie2 mice would also increase thrombus occlusion time and provide a mechanism explaining why psoriasis patients have an increased risk of developing and dying of cardiac events. However, KC-Tie2xMrp14 ${ }^{-1-}$ mice maintained shortened occlusion times at levels similar to those of KC-Tie2 mice, suggesting that MRP14 never contributed to the etiology of the hypercoagulable phenotype in the

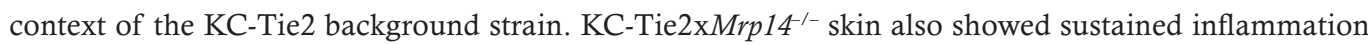
and elevated expression of IL-23, IL-17A, and IL-6 (15), confirming recent reports showing a similar lack of improvement in psoriasiform skin inflammation in K14-Angptl6 transgenic mice following the genetic deletion of Mrp14 (30), but contradicting reports in which Mrp14 was eliminated from epidermal 
A

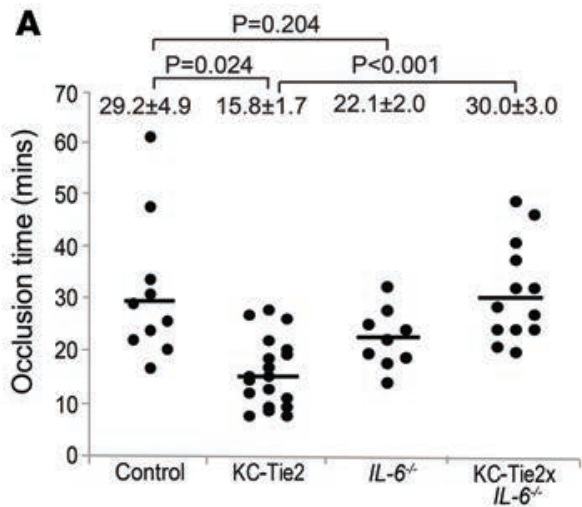

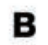

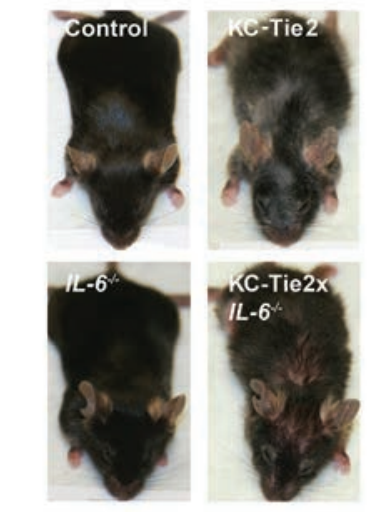

D

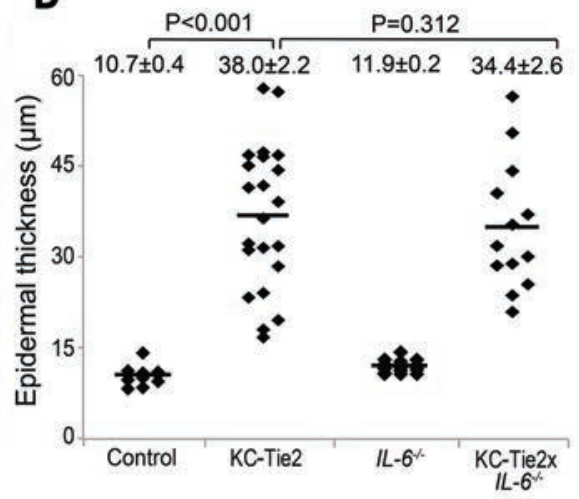

Figure 4. IL-6 deficiency prolongs thrombus occlusion formation independent of skin inflammation in KC-Tie2 mice. (A) Occlusion times (minutes) following rose bengal-elicited photochemical injury of the carotid artery in control $(n=10)$, KC-Tie2 $(n=20), I L-6^{-/-}(n=9)$, and KC-Tie2xIL-6 $6^{-/-}(n=13)$ mice. (B) Representative gross images of the skin phenotype of control, KC-Tie2, IL-6-/, and KC-Tie2x $I L-6^{-/-}$mice. (C) Representative images of dorsal skin sections of

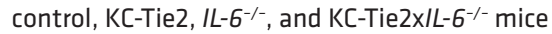
that were stained using CD11b-specific antibodies. Scale bar: $25 \mu \mathrm{m}$. (D) Quantification of epidermal thickness $(\mu \mathrm{m})$ of dorsal skin sections of control $(n=12)$, KC-Tie2 ( $n=22), I L-6^{-/-}(n=17)$, and KC-Tie2xIL- $6^{-/-}(n=13)$ mice. Values shown represent the mean \pm SEM. Each dot represents 1 individual mouse. Data were analyzed using a Student's $t$ test. $P$ values are as indicated.

double deletion of keratinocyte-JunB and Jun mice (DKO), demonstrating modelspecific responsiveness (15).

The persistence of the inflammatory skin phenotype, and the shifts in cytokine expression of IL-23, IL-17A, and IL-6 in KC-Tie2xMrp $14^{-1-}$ mice suggests that these cytokines may sustain both the skin inflammation and prothrombotic phenotypes of

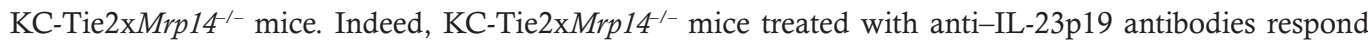
with a reversal of the inflammatory skin phenotype (modeling psoriasis patient response to anti-IL-23p19 therapy; see ref. 31) along with protection from thrombosis, likely primarily mediated through decreases in skin IL-6. Other studies in psoriasis patients have demonstrated that antibodies targeting IL-12/23 or IL-23 decrease IL-17A, and IL-17A regulates the expression of IL-6, a key inflammatory molecule $(31,32)$. We have previously reported that targeted reversal of KC-Tie 2 mouse skin inflammation, and resultant decreases in IL-23, IL-17A, and IL-6 (22) also correspond to a lengthening (or improvement) of time to occlusive thrombus (17). These findings suggest that aggressively targeting skin inflammation improves carotid artery thrombosis, potentially through decreases in skin IL-6.

However, skin inflammation failed to improve in KC-Tie2xIL- $6^{-1-}$ and K5-IL-17CxIL- $6^{-1-}$ mice, despite the return to control mouse levels for thrombosis clotting times. The cutaneous observations contradict prior findings in acute models of elicited psoriasiform skin inflammation in which IL-6, through promotion of IL-22 responses, may facilitate IL-23-mediated epidermal hyperproliferation (33). This alternative pathway has been reported to work even in the absence of IL-17A in the imiquimod psoriasiform model (34). The

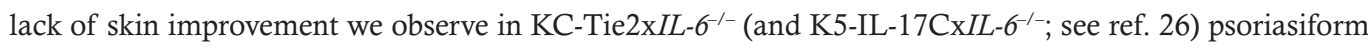
animal models is highly consistent with human trials, where blockade of IL-6 fails to improve psoriasis severity, and in some instances, causes psoriasis flares (24, 35-38), perhaps due to increases in alternative proinflammatory cytokines (26). Differences in model systems may account for the different outcomes, such that IL-23 and imiquimod psoriasiform models are acute and elicited, whereas KC-Tie2 and K5-IL17C models are chronic and occur spontaneously in response to transgene overexpression. Recent work also now suggests that intradermal IL-23-mediated epidermal hyperplasia may more closely reflect atopic dermatitis (39).

The results from KC-Tie $2 \times I L-6^{-1-}$ mice demonstrate the ability to separate skin inflammation from thrombus occlusion times and identify IL- 6 as a critical promoter of carotid artery thrombosis occlusion, independent of acanthosis and cutaneous immune cell infiltration. However, unlike Mrp $14^{-1-}$ mice, $I L-6^{-1-}$ mice had clotting times similar to those of C57BL/6 mice, suggesting that it is increases in skin-derived IL- 6 that are critical for the promotion of thrombosis. We confirmed this concept in K5-IL-17CxIL- $6^{-1-}$ mice in which IL-6 deletion also increased occlusion times independent of sustained skin inflammation. Others have 


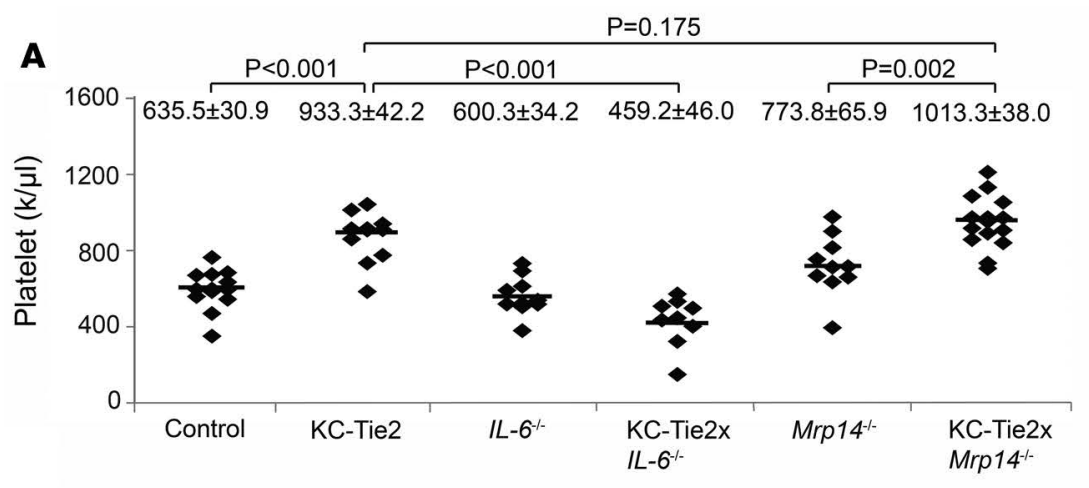

B

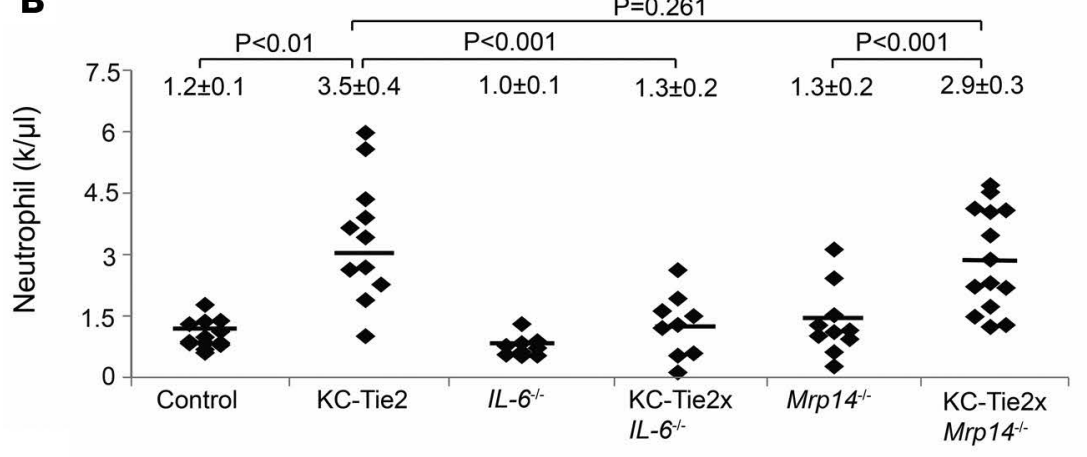

C

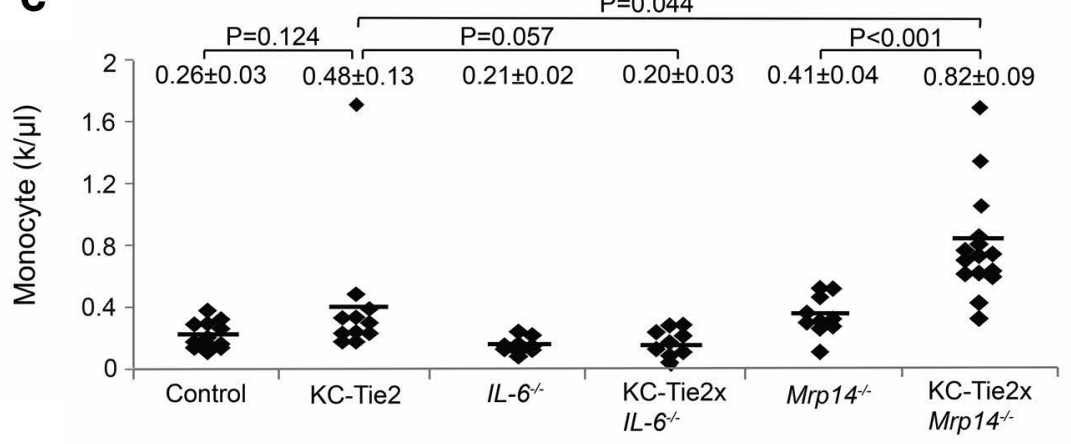

D

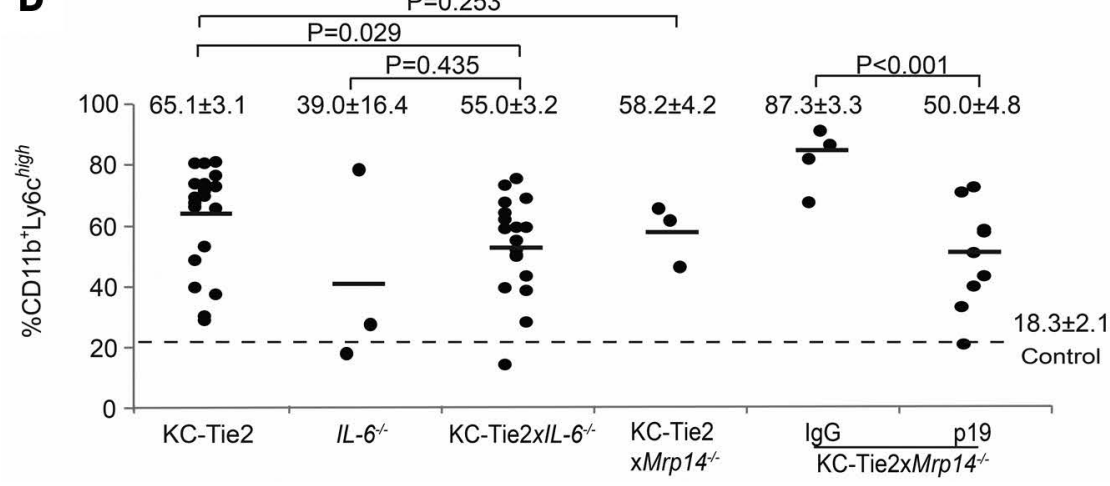

Figure 5. Mrp14 and IL-6 deficiency in KC-Tie2 mice and IL-23p19 inhibition in KC-Tie2xMrp14/-- mice have differential effects on blood concentrations of platelets, neutrophils, and monocytes and skin draining lymph node monocyte levels. (A) Platelet, (B) neutrophil, and (C) monocyte counts (thousand per microliter) from fresh blood of control $(n=13)$, KC-Tie2 ( $n=11), I L-6^{-/-}(n=10)$, KC-Tie2xIL-6 ${ }^{-/-}(n=$

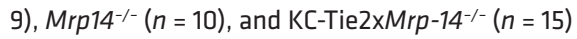
mice. (D) Quantification of CD11b+Ly6C hi monocytes in lymph nodes of KC-Tie2 $(n=19), \mathrm{IL}_{-} \mathrm{G}^{-/-}(n=3)$, KC-Tie2xIL-6 ${ }^{-/-}(n=19)$, KC-Tie2x Mrp14 ${ }^{-/-}(n=3)$, and KC-Tie2x Mrp14-/- mice treated with control IgC $(n=5)$ or anti-IL-23p19 antibody $(n=9)$. Values shown represent the mean \pm SEM. Dotted line represents archived values of WT control $(n=7)$. Mrp14 $1-$ animals ( $n=3$ pooled samples of 3 animals each) had undetectable levels. Each dot represents 1 individual sample. Data were analyzed using a Student's $t$ test. $P$ values are as indicated.

also reported improvement in ROS levels in the blood, cardiac NADPH oxidase activity, and endothelial dysfunction following IL-6 inhibition in K14-IL-17A $\mathrm{A}^{\text {ind/+ }}$ mice, another skindriven psoriasis-like mouse model, although they observed improvement in the skin phenotype (40), showing the complexity and diversity of psoriasis mouse models.

A role for elevated IL- 6 in promotion of secondary thrombosis and thrombocytosis has been previously identified in psoriasis, irritable bowel disease, and rheumatoid arthritis (for review see ref. 41). In lesional psoriasis skin, IL-6 localizes to endothelial cells, keratinocytes, and leukocytes in lesional psoriasis skin, and IL- 6 derived from activated dendritic cells rebalances STAT3/STAT1 ratios, thereby facilitating the escape of $\mathrm{T}$ memory/effector cells from Treg-mediated suppression $(42,43)$, contributing to skin inflammation in psoriasis. Treatment of psoriasis patients with TNF- $\alpha$ inhibitors is highly efficacious at improving the severity of the skin disease and normalizes psoriasis patient platelet counts by reducing systemic IL-6 levels (41). Similar normalization of platelet counts following IL-6 inhibition has recently been demonstrated (38). These findings are consistent with the decreases in platelet counts we observed in $\mathrm{KC}-\mathrm{Tie} 2 \mathrm{x} I \mathrm{~L}-\mathrm{\sigma}^{-1-}$ mice

and support a role for elevated IL-6 and thrombocytosis in mediating the thrombosis outcome. Indeed, elevated plasma IL-6 levels are associated with increased myocardial infarction risk (44). We and others (42, 45-48) have shown elevated skin and serum IL-6 in psoriasis patients and data presented here demonstrate the presence of IL-6R in human coronary atheroma, supporting a link between skin and distant vessel disease in patient tissue. However, the connection between circulating IL-6 levels and cardiovascular outcomes is largely dependent upon the duration of the signal, i.e., chronicity $(49,50)$. This observation is consistent with our prior findings that chronic and not acute skin-initiated inflammation is required to promote 
A

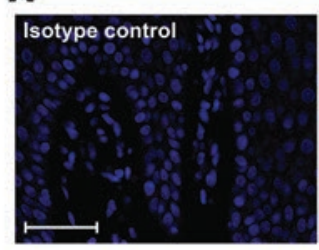

B

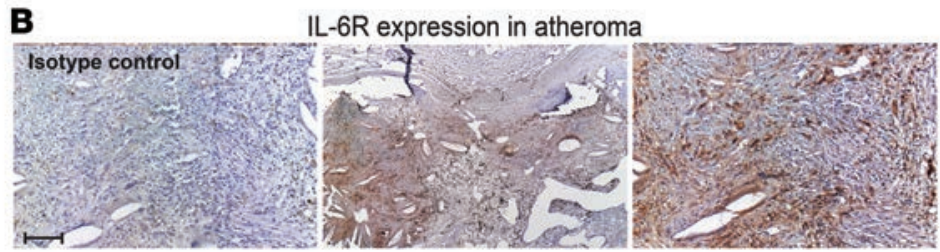

IL-6 expression

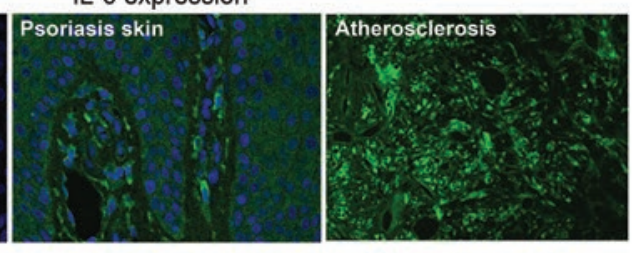

Figure 6. IL-6 levels increase in human psoriasis plaque and IL-6 and its receptor are present in human coronary atheroma plaque. (A) Representative microscopic images of IL-6 immunofluorescence staining in psoriasis lesional plaque $(n=5)$ and in coronary atherosclerotic plaque $(n=4)$. (B) Representative microscopic images of the expression of IL-6 receptor (IL-6R) using immunohistochemistry in human atherosclerotic tissues $(n=4)$. Scale bar in A: $50 \mu \mathrm{m}$ for left and middle panels and $150 \mu \mathrm{m}$ for the right panel. Scale bar in B: $100 \mu \mathrm{m}$ for left and right panels and $400 \mu \mathrm{m}$ for middle panel.

a shortening in thrombosis clotting times (27). In fact, acute IL-6 signaling is known to have a protective effect versus the deleterious effects of chronic IL-6 exposure on cardiac myocytes (51-55) and appears to correlate with downstream IL-6 signaling and regulation of STAT3/STAT1 levels and SOCS3 expression. Overexpression of SOCS2 in cultured cardiac myocytes suppresses IL-6 signaling, and blocks IL-6-family cytokines from inhibiting apoptosis and induces hypertrophy (56). Finally, inhibition of IL-6/IL-6R signaling using tocilizumab results in improved arterial flow and decreased aortic stiffness (57), decreased lipid particle levels (LDL, HDL, VLDL) and composition (HDL-associated serum amyloid A), coupled with changes in inflammatory and vascular risk factors, such as C-reactive protein and paraoxonase 1 (PON1), and decreased thrombotic potential evidenced by reductions in circulating fibrinogen and D-dimers (58), consistent with the idea that IL-6 modulation can decrease cardiovascular risk in patients. These findings support our murine results, in which elimination of IL-6 in 2 chronic psoriasiform models lengthened thrombosis clotting times, and where anti-IL-23p19 treatment of $\mathrm{KC}$-Tie $2 \times \mathrm{Mrp} 14^{--}$mice resulted in a protection from thrombosis, likely primarily mediated through decreases in skin IL-6 production. The long-term effects of IL- 6 overproduction can be appreciated in patients with autoimmune myocarditis who may develop dilated cardiomyopathy. Increased IL-6 levels reflect the severity of the heart failure (59). Indeed, IL-6 has been reported to increase in heart tissue of dilated cardiomyopathy and heart failure patients (60-62). Thus, the connection of IL-6 levels to heart failure and heart disease is substantial and may explain our observed improvement in thrombosis following IL-6 deletion.

We previously reported increases in proinflammatory CD11b ${ }^{+}$y6 $6 C^{\text {hi }}$ monocytes in KC-Tie2 mice (17, 63) that precede the development of aortic root inflammation and shortened arterial thrombosis times, leading us to speculate that monocytes may participate in the thrombus formation. In mice with lengthened (protected) thrombosis clotting times (KC-Tie2xIL- $6^{--}$), we observed modest decreases in proinflammatory CD11b ${ }^{+}$Ly6 $C^{\text {hi }}$ monocytes; however, these decreases occurred concomitantly with much larger reductions in circulating platelets and neutrophils, suggesting perhaps a more critical role for these cells in the promotion of thrombosis versus the monocytes. Indeed, in $\mathrm{KC}$-Tie $2 \mathrm{xMrp} 14^{-1}$ mice where skin inflammation was sustained and thrombosis clotting times were very short, $C D 11 b^{+} L y 6 C^{\text {hi }}$ monocytes, neutrophils, and platelet levels remained significantly elevated. Moreover, recent work showed that acute skin inflammation elicited by topical imiquimod application also caused elevated systemic monocytosis, but failed to shorten thrombosis clotting times (27), whereas chronic exposure to skin inflammation shortened clotting times and this correlated better with neutrophilia (platelet levels were not examined). These findings suggest that proinflammatory $\mathrm{CD} 11 \mathrm{~b}^{+} \mathrm{Ly} 6 \mathrm{C}^{\text {hi }}$ monocytes better reflect activity of skin inflammation rather than thrombosis potential, and that platelets and neutrophils are more likely the pathogenic participant in the promotion of thrombosis. Support for this is seen in that neutrophil and platelet counts both decrease in KC-Tie $2 \times I L-6^{-1-}$ mice that had lengthened clotting times, independent of a sustained psoriasiform phenotype, consistent with a more important role for skin-derived IL-6 effects on platelets and/or neutrophils, or the interaction of these cells, within and amongst themselves (64). Indeed, neutrophil depletion in a murine model of stroke triggered by permanent occlusion of the middle cerebral artery significantly reduced tissue death (64), and prevention of neutrophil extracellular trap formation normalized arterial thrombosis clotting times to control mouse levels $(65,66)$.

In summary, our study demonstrates a critical role for IL- 6 signaling and increased numbers of circulating platelets and leukocytes in promoting thrombosis that is associated with psoriasiform inflammation. KC-Tie2 mice backcrossed with $\mathrm{Mrp}_{14^{-/}}$mice develop levels of skin inflammation similar to those of KCTie2 mice and remain prothrombotic, likely as a result of sustained increases in proinflammatory IL-23 and 
IL-6. Deletion of IL-6 improved thrombosis, despite sustained skin inflammation, suggesting the concomitant decrease in circulating neutrophils and platelets may direct thrombosis via IL-6 signaling response. IL-23p19 inhibition also improved thrombosis likely through decreased IL-6 levels. Taken together, our data support a critical function for skin-derived IL- 6 in the promotion of occlusive thrombosis in 2 unique chronic mouse models of psoriasiform skin. Moreover, we have extended these results to human samples and demonstrate the presence of IL-6R in atheroma and elevated IL-6 in psoriasis lesional skin, providing further support in patient tissues for a potential link between skin and distant vessel disease. Of translational importance, our findings provide evidence that targeting IL-6 in chronic skin inflammation may offset cardiovascular disease risk, and that skin inflammation can be disconnected from the cardiovascular comorbidities by targeting IL-6. These findings may have major therapeutic implications.

\section{Methods}

Mice. K5tTA, Tet ${ }^{\text {os }} \mathrm{Tie} 2$, Tet ${ }^{\mathrm{os}} \mathrm{IL}-17 \mathrm{C}, \mathrm{Mrp}^{14^{--}}$, and $I L-6^{-/-}$mouse engineering has been previously described $(22,25,67,68)$. The Tet ${ }^{\text {os }}$ Tie2 line was backcrossed with C57BL/ 6 mice for more than 10 generations before use in the current experiments. Individual driver tTA and Tet ${ }^{\text {os }}$ responder mouse lines (BL/6 background) were mated with either $M r p 14^{-1}$ mice (67) or $I L-6^{-1-}$ mice (JAX, catalog 002650) to generate K5tTA-, Tet ${ }^{\text {os Tie2-, }}$ or Tet ${ }^{\text {os }} \mathrm{IL}-17 \mathrm{C}-$ homozygous $\mathrm{Mrp} 14^{-1-}$ or $I L-6^{-1-}$ mice. The K5tTA line was then mated with either the Tet ${ }^{\text {os }}$ Tie 2 or Tet ${ }^{\text {os }} \mathrm{IL}-17 \mathrm{C}$ responder lines in the presence of doxycycline $(200 \mathrm{mg} / \mathrm{kg}$, cata$\log$ S3888, Bio-Serv) to repress transgene expression for the first week of gestation (KC-Tie2) or until birth (K5-IL-17C), and then food was replaced with regular P3000 diet. Similar approaches were used to gener-

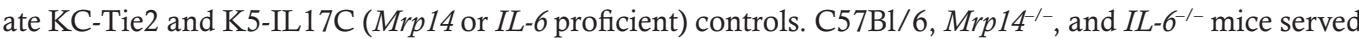
as additional background strain controls. Male and female mice were used for all experimental analyses. Genotyping of all mice was done as previously described $(22,25,67)$. Mice that inherited a single, nonexpressing gene (either K5tTA, Tet ${ }^{\text {os }} \mathrm{Tie} 2$, or $\mathrm{Tet}^{\mathrm{os}} \mathrm{IL}-17 \mathrm{C}$ ) did not differ from control mice of the same genetic background strain (C57BL/6, Mrp $14^{-/-}$, and $I L-6^{--}$) and also served as littermate control animals.

Six-week-old KC-Tie2xMrp14-- mice were treated once per week systemically (i.p.) for a 6-week period with either function-blocking antibodies targeting IL-23p19 (2 mg/ $\mathrm{kg})$ or murine IgG isotype control ( $2 \mathrm{mg} / \mathrm{kg})$, provided by Kristine Kikly (Eli Lilly, Indianapolis, Indiana, USA) and then underwent carotid arterial thrombosis.

Murine model of carotid arterial thrombosis. The carotid arterial thrombosis assay was completed as previously described $(6,17,69)$. Briefly, deeply anesthetized mice were placed in the supine position on a dissecting microscope. A cervical midline surgical incision was made to expose the right common carotid artery and a Doppler flow probe (MC 0.5PSL Nanoprobe, Model 0.5 VB, Transonic Systems) was placed under the carotid artery. The probe was connected to a flowmeter (Transonic Systems Model TS420). Rose bengal at a concentration of $10 \mathrm{mg} / \mathrm{ml}$ in phosphate-buffered saline was then injected into the tail vein to administer a dose of $50 \mathrm{mg} / \mathrm{kg}$. The mid portion of the common carotid artery was then illuminated with a 1.5 - $\mathrm{mW}$ green light laser source (540 nm, Melles Griot). Blood flow was monitored continuously from the onset of injury. The time to occlusion, determined only after the vessel remained closed with a cessation of blood flow for 10 minutes, was recorded.

Tissue collection, histological and immunostaining analyses. Skin was collected and processed as described previously for histology and immunohistochemistry $(22,25)$. Formalin-fixed paraffin-embedded skin was sectioned and stained with H\&E as described previously (22). Fresh frozen skin was sectioned and stained also using protocols previously published $(21,22,25)$ using antibodies targeting the following proteins: CD4 (clone RM4-5, catalog 550280), CD8a (clone 53-6.7, catalog 550281), CD11b (clone M1/70, catalog 550282), CD11c (clone HL3, catalog 550283) (all BD Pharmingen), F4/80 (clone BM8, catalog 14-4801, eBioscience), and Ki67 (clone Tec-3, catalog M7249, DakoCytomation).

Epidermal thickness (acanthosis) measurements and immune cell quantification in the skin were done using microscopic images collected from the stained sections using interactive image analyses approaches as previously described $(21,22)$.

ELISA and Western blotting. Protein was isolated from skin adjacent to that used for histological and immunostaining analyses using standard protocols previously described $(22,25)$. Skin lysate proteins were measured using commercially available ELISA kits targeting IL-6, IL-17A (R\&D Systems), or IL-12/23p40 (eBiosciences) according to the manufacturer's instructions. Western blotting of murine Tie2 (clone C-20, catalog sc-324, Santa Cruz Biotechnology), Mrp14 (clone 372510, catalog MAB2065, R\&D Systems), and GAPDH (clone 14C10, catalog 2118, Cell Signaling Technology) skin protein was completed as previously described $(22,25)$. 
$R N A$ and $q R T-P C R$ on murine skin. RNA was isolated from skin adjacent to that used for histology, immunostaining, and protein analyses using the RNeasy Mini Kit (Qiagen) according to the manufacturer's instructions. First-strand cDNA synthesis was accomplished using MMLV reverse transcriptase (Invitrogen) following the manufacturer's protocol. Quantitative real-time PCR was performed using Taqman technology from Applied Biosystems on an ABI Prism 7700 Sequence Detector. Probes and primers were obtained from Applied Biosystems. Expression levels were calculated relative to mouse $\beta$-actin using the comparative Ct method $(\Delta \Delta \mathrm{CT})$.

Complete blood counts. For all experimental mouse groups, citrate-anticoagulated blood was drawn from a separate cohort of animals distinct from that used for thrombosis assessment and $100 \mu 1$ (from a total volume of $\sim 0.7$ to $1.0 \mathrm{ml}$ ) was run in duplicate on a Veterinary Multi-species Hematology System (Hemavet HV950FS, Drew Scientific Group).

Flow cytometry. Cells from skin draining lymph nodes were isolated as previously described (27) and stained for cell surface markers: Ly6C (Alexa Fluor 488, clone HK1.4, catalog 128022, Biolegend) and isotype control Alexa Fluor 488 Rat IgG2c, $\kappa$ Isotype (catalog 400715, Biolegend); Ly6G (Alexa Fluor 700; clone 1A8, catalog 561236, BD Biosciences) and isotype control Alexa Fluor 700 Rat IgG2a, $\kappa$ Isotype (catalog 400528, Biolegend); and CD11b (APC; clone M1/70, catalog 17-0112-83, eBiosciences) and isotype control APC Rat IgG2b, $\kappa$ Isotype (catalog 400612, Biolegend). Flow cytometry data collection was performed using a BD LSRII or FACS ARIA instrument and analyzed using FlowJo software v10 (Tree Star). For cell gating, monocytes and neutrophils were gated as previously described (27), using a fixable viability dye (FV450, BD Biosciences) to exclude dead cells. Monocytes were classified as expressing CD $11 b^{+}$Ly6 $6 G^{\text {lo }}{ }^{2} 6 C^{\text {hi }}$, while neutrophils expressed $C D 11 b^{+} L y 6 G^{\text {hi }} L y 6 C^{\text {lo }}$. Supplemental Figure 4 shows the gating strategy used in the current study.

Human skin and atheroma studies. Skin samples were obtained from affected (lesional) skin from patients with active plaque psoriasis $(n=5)$. Patients were off all systemic treatments for at least 1 month, and all topical treatments 2 weeks prior to biopsy. Biopsies were formalin fixed and paraffin embedded. Samples from atherosclerotic coronary arteries $(n=4)$ and healthy coronary vascular tissue $(n=4)$ were obtained from discarded tissue from heart transplant operations, formalin fixed, and subsequently paraffin embedded. Immunohistochemistry was performed on 5- $\mu \mathrm{m}$-thick paraffin sections using antibodies against IL-6 (clone 10C12, catalog NCL-L-IL6, Leica Biosystems) and IL-6R (catalog LS-B6362, Lifespan Biosciences Inc.).

Statistics. Comparisons between groups for acanthosis, immune cell density, thrombosis clotting times, and ELISA were performed using an unpaired, 2-tailed, unequal variance Student's $t$ test, except where otherwise indicated. qRT-PCR data were analyzed using a nonparametric Mann-Whitney $U$ test. $P$ values less than 0.05 were considered significant. Data are presented as the mean \pm SEM.

Study approval. Animal protocols were consistent with guidelines issued by the American Association for Accreditation of Laboratory Animal Care and were approved by the Case Western Reserve University IACUC. All human subject protocols were approved by the IRBs of the University of Michigan or Case Western Reserve University, and written informed consent was received from participants prior to inclusion in the study.

\section{Author contributions}

YW, JBG, YF, TSM, and NLW designed the studies. YW, JBG, YF, SMD, MIC, XZ, DD, XX, JEG, and NLW performed the experiments and collected the data. SKG collected the human atherosclerotic plaque. YW, JBG, JEG, DIS, TSM, and NLW generated the figures and wrote the paper.

\section{Acknowledgments}

This work was supported in part by The Lozick Discovery Grant, National Psoriasis Foundation, the Murdough Family Center for Psoriasis, the National Institute of Arthritis and Musculoskeletal and Skin Diseases of the NIH (grants P30 AR39750, P50 AR055508, R01 AR063437, R01 AR062546, R21 AR063852, K08 AR060802, and R01 AR069071), the National Institute for Heart, Lung and Blood of the NIH (R01 HL057506 and R01 HL126645), the A. Alfred Taubman Medical Research Institute, the Kenneth and Frances Eisenberg Emerging Scholar Award, and the Babcock Foundation Endowment.

Address correspondence to: Nicole L. Ward, Case Western Reserve University, Department of Dermatology, BRB519, 10900 Euclid Avenue, Cleveland, Ohio 44106, USA. Phone: 216.368.1111; E-mail: nlw4@cwru.edu. 
1. Vogl T, et al. Alarmin S100A8/S100A9 as a biomarker for molecular imaging of local inflammatory activity. Nat Commun. 2014;5:4593.

2. Gebhardt C, Németh J, Angel P, Hess J. S100A8 and S100A9 in inflammation and cancer. Biochem Pharmacol. 2006;72(11):1622-1631.

3. Croce $\mathrm{K}$, et al. Myeloid-related protein-8/14 is critical for the biological response to vascular injury. Circulation. 2009;120(5):427-436.

4. Morrow DA, et al. Myeloid-related protein 8/14 and the risk of cardiovascular death or myocardial infarction after an acute coronary syndrome in the Pravastatin or Atorvastatin Evaluation and Infection Therapy: Thrombolysis in Myocardial Infarction (PROVE IT-TIMI 22) trial. Am Heart J. 2008;155(1):49-55.

5. Healy AM, et al. Platelet expression profiling and clinical validation of myeloid-related protein-14 as a novel determinant of cardiovascular events. Circulation. 2006;113(19):2278-2284.

6. Wang Y, et al. Platelet-derived S100 family member myeloid-related protein-14 regulates thrombosis. J Clin Invest. 2014;124(5):2160-2171.

7. Ahlehoff $\mathrm{O}$, et al. Psoriasis and risk of atrial fibrillation and ischaemic stroke: a Danish nationwide cohort study. Eur Heart J. 2012;33(16):2054-2064.

8. Ahlehoff $\mathrm{O}$, et al. Psoriasis carries an increased risk of venous thromboembolism: a Danish nationwide cohort study. PLoS One. 2011;6(3):e18125.

9. Gelfand JM, Neimann AL, Shin DB, Wang X, Margolis DJ, Troxel AB. Risk of myocardial infarction in patients with psoriasis. JAMA. 2006;296(14):1735-1741.

10. Mehta NN, Azfar RS, Shin DB, Neimann AL, Troxel AB, Gelfand JM. Patients with severe psoriasis are at increased risk of cardiovascular mortality: cohort study using the General Practice Research Database. Eur Heart J. 2010;31(8):1000-1006.

11. Mehta NN, et al. Attributable risk estimate of severe psoriasis on major cardiovascular events. Am J Med. 2011;124(8):775.e1-775.e6.

12. Semprini S, et al. Evidence for differential S100 gene over-expression in psoriatic patients from genetically heterogeneous pedigrees. Hum Genet. 2002;111(4-5):310-313.

13. Hansson C, Eriksson C, Alenius GM. S-calprotectin (S100A8/S100A9): a potential marker of inflammation in patients with psoriatic arthritis. J Immunol Res. 2014;2014:696415.

14. Benoit S, et al. Elevated serum levels of calcium-binding S100 proteins A8 and A9 reflect disease activity and abnormal differentiation of keratinocytes in psoriasis. Br J Dermatol. 2006;155(1):62-66.

15. Schonthaler HB, et al. S100A8-S100A9 protein complex mediates psoriasis by regulating the expression of complement factor C3. Immunity. 2013;39(6):1171-1181.

16. Zenz R, et al. Psoriasis-like skin disease and arthritis caused by inducible epidermal deletion of Jun proteins. Nature. 2005;437(7057):369-375.

17. Wang Y, et al. Chronic skin-specific inflammation promotes vascular inflammation and thrombosis. J Invest Dermatol. 2012;132(8):2067-2075.

18. Lundberg KC, et al. Proteomics of skin proteins in psoriasis: from discovery and verification in a mouse model to confirmation in humans. Mol Cell Proteomics. 2015;14(1):109-119.

19. Swindell WR, et al. Genome-wide expression profiling of five mouse models identifies similarities and differences with human psoriasis. PLoS One. 2011;6(4):e18266.

20. Ward NL, et al. Erlotinib-induced skin inflammation is IL-1 mediated in KC-Tie2 mice and human skin organ culture. J Invest Dermatol. 2015;135(3):910-913.

21. Ward NL, Loyd CM, Wolfram JA, Diaconu D, Michaels CM, McCormick TS. Depletion of antigen-presenting cells by clodronate liposomes reverses the psoriatic skin phenotype in KC-Tie2 mice. Br J Dermatol. 2011;164(4):750-758.

22. Wolfram JA, et al. Keratinocyte but not endothelial cell-specific overexpression of Tie2 leads to the development of psoriasis. Am J Pathol. 2009;174(4):1443-1458.

23. Blauvelt A, Lebwohl MG, Bissonnette R. IL-23/IL-17A dysfunction phenotypes inform possible clinical effects from anti-IL17A therapies. J Invest Dermatol. 2015;135(8):1946-1953.

24. Hartung W, Ehrenstein B, Wallisch R, Fleck M. Remission of arthritis but persistent cutaneous lesions following tocilizumab treatment in a RA-patient suffering from concomitant psoriasis. Case Reports in Clinical Medicine. 2013;2(1):63-65.

25. Johnston A, et al. Keratinocyte overexpression of IL-17C promotes psoriasiform skin inflammation. J Immunol. 2013;190(5):2252-2262.

26. Fritz Y, et al. Induction of alternative proinflammatory cytokines accounts for sustained psoriasiform skin inflammation in IL$17 \mathrm{C}^{+} \mathrm{IL}-6 \mathrm{KO}$ mice. J Invest Dermatol. In Press.

27. Golden JB, et al. Chronic, not acute, skin-specific inflammation promotes thrombosis in psoriasis murine models. J Transl Med $2015 ; 13: 382$.

28. Hashizume M, Mihara M. Atherogenic effects of TNF- $\alpha$ and IL-6 via up-regulation of scavenger receptors. Cytokine. 2012;58(3):424-430.

29. Mani V, et al. Predictors of change in carotid atherosclerotic plaque inflammation and burden as measured by $18-\mathrm{FDG}-\mathrm{PET}$ and MRI, respectively, in the dal-PLAQUE study. Int J Cardiovasc Imaging. 2014;30(3):571-582.

30. Tanigawa H, et al. Upregulation of ANGPTL6 in mouse keratinocytes enhances susceptibility to psoriasis. Sci Rep. 2016;6:34690.

31. Krueger JG, et al. Anti-IL-23A mAb BI 655066 for treatment of moderate-to-severe psoriasis: Safety, efficacy, pharmacokinetics, and biomarker results of a single-rising-dose, randomized, double-blind, placebo-controlled trial. J Allergy Clin Immunol. 2015;136(1):116-124.e7.

32. Sofen H, et al. Guselkumab (an IL-23-specific mAb) demonstrates clinical and molecular response in patients with moderate-tosevere psoriasis. J Allergy Clin Immunol. 2014;133(4):1032-1040.

33. Lindroos J, et al. IL-23-mediated epidermal hyperplasia is dependent on IL-6. J Invest Dermatol. 2011;131(5):1110-1118.

34. El Malki K, et al. An alternative pathway of imiquimod-induced psoriasis-like skin inflammation in the absence of interleukin-17 receptor a signaling. J Invest Dermatol. 2013;133(2):441-451. 
35. Laurent S, Le Parc JM, Clérici T, Bréban M, Mahé E. Onset of psoriasis following treatment with tocilizumab. Br J Dermatol. 2010;163(6):1364-1365.

36. Grasland A, Mahé E, Raynaud E, Mahé I. Psoriasis onset with tocilizumab. Joint Bone Spine. 2013;80(5):541-542.

37. Wendling D, Letho-Gyselinck H, Guillot X, Prati C. Psoriasis onset with tocilizumab treatment for rheumatoid arthritis. JRheumatol. 2012;39(3):657.

38. Mease $\mathrm{P}$, et al. The efficacy safety of clazakizumab, an anti-interleukin- 6 monoclonal antibody, in a phase $2 \mathrm{~b}$ study of adults with active psoriatic arthritis. Arthritis Rheumatol. 2016;68(9):2163-2173.

39. Ewald DA, et al. Major differences between human atopic dermatitis murine models as determined by global transcriptomic profiling [published online ahead of print October1, 2016]. J Allergy Clin Immunol. doi: 10.1016/j.jaci.2016.08.029.

40. Karbach S, et al. Interleukin 17 drives vascular inflammation, endothelial dysfunction, and arterial hypertension in psoriasis-like skin disease. Arterioscler Thromb Vasc Biol. 2014;34(12):2658-2668.

41. Davidovici BB, Sullivan-Whalen MM, Gilleaudeau P, Krueger JG. Differing effect of systemic anti psoriasis therapies on platelet physiology--a case report and review of literature. BMC Dermatol. 2010;10:2.

42. Goodman WA, Levine AD, Massari JV, Sugiyama H, McCormick TS, Cooper KD. IL-6 signaling in psoriasis prevents immune suppression by regulatory T cells. J Immunol. 2009;183(5):3170-3176.

43. Goodman WA, Young AB, McCormick TS, Cooper KD, Levine AD. Stat3 phosphorylation mediates resistance of primary human T cells to regulatory T cell suppression. J Immunol. 2011;186(6):3336-3345.

44. Ridker PM, Rifai N, Stampfer MJ, Hennekens CH. Plasma concentration of interleukin-6 and the risk of future myocardial infarction among apparently healthy men. Circulation. 2000;101(15):1767-1772.

45. Alenius GM, Eriksson C, Rantapää Dahlqvist S. Interleukin-6 and soluble interleukin-2 receptor alpha-markers of inflammation in patients with psoriatic arthritis? Clin Exp Rheumatol. 2009;27(1):120-123.

46. Grossman RM, et al. Interleukin 6 is expressed in high levels in psoriatic skin and stimulates proliferation of cultured human keratinocytes. Proc Natl Acad Sci U S A. 1989;86(16):6367-6371.

47. Neuner P, et al. Increased IL-6 production by monocytes and keratinocytes in patients with psoriasis. J Invest Dermatol. 1991;97(1):27-33

48. Castells-Rodellas A, Castell JV, Ramirez-Bosca A, Nicolas JF, Valcuende-Cavero F, Thivolet J. Interleukin-6 in normal skin and psoriasis. Acta Derm Venereol. 1992;72(3):165-168.

49. Fontes JA, Rose NR, Čiháková D. The varying faces of IL-6: From cardiac protection to cardiac failure. Cytokine. 2015;74(1):62-68

50. Danesh J, et al. Long-term interleukin-6 levels and subsequent risk of coronary heart disease: two new prospective studies and a systematic review. PLoS Med. 2008;5(4):e78.

51. Wollert KC, et al. Cardiotrophin-1 activates a distinct form of cardiac muscle cell hypertrophy. Assembly of sarcomeric units in series VIA gp130/leukemia inhibitory factor receptor-dependent pathways. J Biol Chem. 1996;271(16):9535-9545.

52. Terrell AM, Crisostomo PR, Wairiuko GM, Wang M, Morrell ED, Meldrum DR. Jak/STAT/SOCS signaling circuits and associated cytokine-mediated inflammation and hypertrophy in the heart. Shock. 2006;26(3):226-234.

53. Wollert KC, Drexler H. The role of interleukin-6 in the failing heart. Heart Fail Rev. 2001;6(2):95-103.

54. Yamauchi-Takihara K, Kishimoto T. Cytokines and their receptors in cardiovascular diseases--role of gp130 signalling pathway in cardiac myocyte growth and maintenance. Int J Exp Pathol. 2000;81(1):1-16.

55. Frangogiannis NG, Smith CW, Entman ML. The inflammatory response in myocardial infarction. Cardiovasc Res. 2002;53(1):31-47.

56. Yasukawa H, et al. Suppressor of cytokine signaling-3 is a biomechanical stress-inducible gene that suppresses gp130-mediated cardiac myocyte hypertrophy and survival pathways. J Clin Invest. 2001;108(10):1459-1467.

57. Protogerou AD, Zampeli E, Fragiadaki K, Stamatelopoulos K, Papamichael C, Sfikakis PP. A pilot study of endothelial dysfunction and aortic stiffness after interleukin-6 receptor inhibition in rheumatoid arthritis. Atherosclerosis. 2011;219(2):734-736.

58. McInnes IB, et al. Effect of interleukin-6 receptor blockade on surrogates of vascular risk in rheumatoid arthritis: MEASURE, a randomised, placebo-controlled study. Ann Rheum Dis. 2015;74(4):694-702.

59. Hirota H, et al. Circulating interleukin-6 family cytokines and their receptors in patients with congestive heart failure. Heart Vessels. 2004;19(5):237-241.

60. Buzás K, Megyeri K, Hõgye M, Csanády M, Bogáts G, Mándi Y. Comparative study of the roles of cytokines and apoptosis in dilated and hypertrophic cardiomyopathies. Eur Cytokine Netw. 2004;15(1):53-59.

61. Plenz G, Song ZF, Reichenberg S, Tjan TD, Robenek H, Deng MC. Left-ventricular expression of interleukin-6 messenger-RNA higher in idiopathic dilated than in ischemic cardiomyopathy. Thorac Cardiovasc Surg. 1998;46(4):213-216.

62. Plenz G, et al. Activation of the cardiac interleukin-6 system in advanced heart failure. Eur J Heart Fail. 2001;3(4):415-421

63. Golden JB, et al. Chronic psoriatic skin inflammation leads to increased monocyte adhesion and aggregation. J Immunol. 2015;195(5):2006-2018.

64. Sreeramkumar V, et al. Neutrophils scan for activated platelets to initiate inflammation. Science. 2014;346(6214):1234-1238.

65. Knight JS, et al. Peptidylarginine deiminase inhibition reduces vascular damage and modulates innate immune responses in murine models of atherosclerosis. Circ Res. 2014;114(6):947-956.

66. Rao AN, Kazzaz NM, Knight JS. Do neutrophil extracellular traps contribute to the heightened risk of thrombosis in inflammatory diseases? World J Cardiol. 2015;7(12):829-842.

67. Hobbs JA, et al. Myeloid cell function in MRP-14 (S100A9) null mice. Mol Cell Biol. 2003;23(7):2564-2576.

68. Diamond I, Owolabi T, Marco M, Lam C, Glick A. Conditional gene expression in the epidermis of transgenic mice using the tetracycline-regulated transactivators tTA and rTA linked to the keratin 5 promoter. J Invest Dermatol. 2000;115(5):788-794.

69. Bluth MJ, et al. Myeloid dendritic cells from human cutaneous squamous cell carcinoma are poor stimulators of T-cell proliferation. J Invest Dermatol. 2009;129(10):2451-2462. 